\author{
JOURNAL OF \\ BEHAVIOR STUDIES IN ORGANIZATIONS
}

\title{
Specification a model for study of intellectual capital
}

\author{
Cruz García Lirios \\ Universidad Autónoma del Estado de México
}

Received: 6 December 2019

Revised: 11 January 2020

Accepted : 13 January 2020

\begin{abstract}
Often, the total quality has been instrumented before being weighted. The strategies even precede a diagnosis in Mexican organizations, but in an opposite sense, the present work set out to establish the reliability and validity of an instrument to measure the perception of total quality based on three indicators related to management, production and transfer of knowledge. A non-experimental study was carried out with a non-probabilistic selection of 124 administrative staff and employees from an organization in central Mexico. From a structural model, it was found that management affects production and this about the total perceived quality, although there are lines of research concerning empathy, commitment, entrepreneurship, satisfaction and happiness in relation to the implementation of continuous improvements to the quality of processes and products.
\end{abstract}

\section{Keywords:}

Client Omission, Control Strategy, Logistics Mistake, Wrong Delivery

\section{Introduction}

The anthropocentric paradigm in which companies circumscribed their total quality control to the demands of the market and the specific demand of their clients, the function of the leader was that of an intermediary who managed and managed the risks without considering the environment or capital nor the possibilities of human or intellectual capital in face of the imbalance that the situation implied (Hernández, Anguiano, Valdés, Limón y García, 2018).

Correspondence:

garcialirios@aol.com 
In the paradigm of sustainability, the total quality lies in the evaluation, certification and accreditation of processes based on the availability of resources, policies against climate change, the effects on environmental public health and the risks inherent in the Industrial production (Sánchez, Hernández, Martínez, Villegas y García, 2018).

While in the old anthropocentric paradigm the responsibility was centered on the leader, the manager or administrator, in the new ecocentric paradigm the responsibility is shared (Hernandez \& Valencia, 2016). This implies a unilateral communication versus a bilateral communication, a unidirectional motivation versus a bidirectional motivation. It is about the confrontation of two cultures, one authoritarian and the other democratic.

Even the new environmental paradigm is distinguished from the previous dominant paradigm by the continuous improvement of processes (Mendoza, Ramirez \& Atriano, 2016). This supposes the entrepreneurship and the innovation of the processes that in the previous paradigm was translated in a resistance to the change. That the responsibility of participation and initiative now concerns all those who integrate the organization (Carreón et al., 2014).

The achievement of a shared responsibility precedes a shared work commitment and a climate of emotional, affective and sentimental relationships regulated and oriented to coexistence, respect, solidarity and support among those who make up the organization (Cruz, Arroyo \& Marmolejo, 2016).

Therefore, there to define quality standards and criteria for its continuous improvement, the organization involves leaders and managers, managers and employees in the objectives, tasks and goals according to the availability of resources, social responsibility and organizational capabilities (Elizarraráz, Molina, Quintero, Sánchez y García, 2018).

The relationships between the variables specified in the theory of perceived quality will be adjusted to the data observed in an organization in central Mexico, since it is a universal asymmetric relationship between the demands of the environment and organizational capacities, which also mark differences between leaders and employees

Although the theory of perceived quality anticipates scenarios of differentiation between the requirements of the environment and the capabilities of the organization, among leaders and employees, the perceptions around the total quality process, as well as control management are different in each organization reason why the relationships established in the theory will not conform to the observations of a case study.

\section{Method}

A descriptive, exploratory and transversal study was carried out. 124 administrative and employees of a for-profit organization in the center of Mexico. 34\% men and $66 \%$ women. $75 \%$ under 29 years old $(M=24,13 \mathrm{SD}=0,18), 15 \%$ between 29 and 65 years old $(M=41,23 \mathrm{SD}=10,17)$ and $5 \%$ over 65 years old $(\mathrm{M}=67,32 \mathrm{SD}=0,16) .22 \%$ with more than 7 working years $(\mathrm{M}=7,12 \mathrm{SD}=0,12), 38 \%$ with less than 7 and more than 3 working years $(\mathrm{M}=4,35 \mathrm{SD}=0,84), 28 \%$ with less than 3 working years $(\mathrm{M}=2,43 \mathrm{SD}=0,93)$.

The Total Perceived Quality Scale of Carreón (2016) was used, which includes four dimensions related to the management, production and the perceived transference of the quality of processes. each reagent includes five answer options that go from 00 it does not look like anything to my organization up to $4=$ it looks a lot like my organization.

The Delphi technique was used for the processing of information and the elaboration of the reagents, comparing and integrating informative information to the total quality, as well as to the opinions of different administrative and employees in an organization for profit in the center of Mexico. 
Subsequently, the surveys were applied in the human resources department as part of the staff recruitment and selection protocol, as well as part of the induction, training and training courses. The confidentiality and anonymity of the respondents was guaranteed in writing, as well as the warning that the results of the study did not affect their economic or work status.

The consistency of the instrument was estimated in terms of its questions from the answers, considering the Cronbach alpha parameter, as well as the Barttlet and KMO tests for adequacy and sphericity as preliminary tests to the validity, which was performed with a method of extraction of main axes with promax rotation. The comparison of the model with adjustment and residual parameters for the hypothesis test.

\section{Results}

The values of internal consistency of the instrument (alpha of 0.782 for the general scale and 0.780 to 0.795 for the subscales) which suggest that in other contexts and study samples the measurement of indicators and factors will be similar in up to $70 \%$ of cases.

Method of extraction of the main axes, promax rotation. Adequacy and Sphericity $\lceil\mathrm{X} 2=452,67$ (56df) $\mathrm{p}=0,000: \mathrm{KMO}=0,770 \mathrm{~J} . \mathrm{M}=$ Average, $\mathrm{DE}=$ Standard Deviation, $\mathrm{A}=$ Alpha, quitting the item value. F1 $=$ Perceived Quality Management (alpha of the 0,780 and the $24 \%$ of the variance explained), F2 $=$ Production Perceived Quality (alpha of the 0,785 and $21 \%$ of the variance explained), $3=$ Perceived Quality Transfer (alpha of the 0,790 and the $16 \%$ of the variance explained), F4= Perception of Total Quality (alpha of the 0,795 and the $11 \%$ of the variance explained). All the items are answered with five response options: $0=$ it does not look like my organization, $1=$ it seems very little to my organization, $2=$ it seems little to my organization, $3=$ it appears in something to my organization, $4=$ it looks a lot like my organization

The perceived management of quality determines the perceived production of quality, but this last factor is determinant of the total perceived quality.

The parameters of adjustment and residual $\int \mathrm{X} 2=123,24$ (23df) $p=0,010 ; \mathrm{GFI}=0,990 ; \mathrm{CFI}=, 991$; $\mathrm{IFI}=0,993$; RMSEA $=0,007 \mathrm{~J}$ suggest the acceptance of the null hypothesis, relative to the relations of dependence between the factors used in the state of the question and demonstrated in the empirical test.

\section{Final considerations}

The contribution of this study to the state of the question lies in the establishment of the reliability and validity of an instrument that measures the perception of management, production, transfer and the totality of the quality of the processes, but the type of non-experimental study, the type of nonprobabilistic selection and the type of exploratory factor analysis limit the results of the study to the sample and the context of the investigation.

It is recommended to extend the study to other contexts and samples, using sophisticated analysis of factors such as the least squares technique in order to confirm the structure that underlies the perception of total quality, configured by three factors related to management, production and the transfer of knowledge.

\section{References}

Carreon, J. Hernandez, J., Garcia, C. Garcia, E., Rosas, F. \& Aguilar, J. (2014). Specifying a digital enterprise model for human development through intensive use of information and communication technologies. Rural Perspectives, 13 (25), 123-155 
Elizarraráz, G., Molina, H. D., Quintero, M. L., Sánchez, R. y García, C. (2018): Discursos en torno a la lucidez organizacional en las alianzas estratégicas y las redes de conocimiento entre mipymes caficultoras el centro de México. Margen, 89, 1-11

Hernandez, A. \& Valencia, R. (2016). Innovation instruments: social networks in the internalization of micro, small and medium - sized Mexican companies. In M, Quintero., Sales, and J. Velázquez, E. (Coord.). Innovation and technology challenges for practical application in companies. (Pp. 47-66). Mexico: Miguel Angel Porrua-UAEMEX.

Hernández, J., Anguiano, F., Valdés, O., Limón, G. A. y García, C. (2018). Confiabilidad y validez de una escala que mide las expectativas de formación profesional. Margen, 89, 1-13

Mendoza, E. Ramirez, L. \& Atriano, R. (2016). Use of media and technology in creating an innovation system for the common good. In M, Quintero., Sales, and J. Velázquez, E. (Coord.). Innovation and technology challenges for practical application in companies. (Pp. 95-114). Mexico: Miguel Angel Porrua-UAEMEX.

Quintero, M., Velázquez, E., Sales, J. \& Padilla, S. (2016). A review of the state of the art on SMEs. What innovation studies? In M, Quintero., Sales, and J. Velázquez, E. (Coord.). Innovation and technology challenges for practical application in companies. (Pp. 31-43). Mexico: Miguel Angel Porrua-UAEMEX.

Robles, C., Alviter, L., Ortega, A. \& Martinez, E. (2016). Culture of quality and innovation in microenterprises. In M, Quintero., Sales, and J. Velázquez, E. (Coord.). Innovation and technology challenges for practical application in companies. (Pp. 11-30). Mexico: Miguel Angel Porrua-UAEMEX.

Sales, J., Quintero, M. Velázquez, E. (2016). Adaptation versus innovation: the formation of industrial districts from rural communities. Santa Cruz Atizapan and Chiconcuac.In M, Quintero., Sales, and J. Velázquez, E. (Coord.). Innovation and technology challenges for practical application in companies. (Pp. 181-199). Mexico: Miguel Angel PorruaUAEMEX.

Sánchez, A., Hernández, T. J., Martínez, E., Villegas, E. y García, C. (2018). Cultura organizacional en microempresas activadoras del desarrollo local. Margen, 89, 1-10

Vazquez, C., Barrientos, B., Quintero, M. Velázquez, E. (2016). Government support for innovation, technology and training for small and medium enterprises in Mexico. In M, Quintero., Sales, and J. Velázquez, E. (Coord.). Innovation and technology challenges for practical application in companies. (Pp. 67-78). Mexico: Miguel Angel Porrua-UAEMEX. 